$$
\text { Pontifícia } \text { Universidade }_{\text {Do Rio de Janeiro }}
$$

Maria Alice Gonçalves Antunes

\title{
O RESPEITO PELO ORIGINAL \\ Uma análise da autotradução a partir do caso de João Ubaldo Ribeiro
}

Tese apresentada ao Programa de Pósgraduação da PUC-Rio como requisito parcial para a obtenção do título de Doutor em Letras.

Orientadora: Profa. Dra. Marcia Amaral Peixoto Martins 


$$
\text { Pontifícia Universidade } \text { Cetólica }_{\text {do Rio de Janeiro }}
$$

\section{Maria Alice Gonçalves Antunes}

\section{O respeito pelo original - uma análise da autotradução a partir do caso de João Ubaldo Ribeiro}

Tese apresentada como requisito parcial para obtenção do grau de Doutor pelo programa de Pós-Graduação em Letras do Departamento de Letras do Centro de Teologia e Ciências Humanas da PUC-Rio. Aprovada pela Comissão Examinadora abaixo assinada.

\section{Profa. Marcia do Amaral Peixoto Martins \\ Orientadora \\ Departamento de Letras - PUC-Rio}

Profa. Maria Paula Frota

Departamento de Letras - PUC-Rio

Profa. Leila Cristina de Mello Darin

Faculdade de Comunicação e Filosofia - PUC-SP

Profa. Maria Aparecida Andrade Salgueiro

Departamento de Letras Anglo Germânicas - UERJ

Prof. José Luís Jobim de Salles Fonseca

Instituto de Letras - UERJ
Prof. Paulo Fernando Carneiro de Andrade Coordenador Setorial do Centro de Teologia e Ciências Humanas - PUC-Rio

Rio de Janeiro, 28 de fevereiro de 2007 
Todos os direitos reservados. É proibida a reprodução total ou parcial do trabalho sem autorização do autor, do orientador e da universidade.

\section{Maria Alice Gonçalves Antunes}

Graduou-se em Letras (Inglês e respectivas literaturas) na UERJ (Universidade do Estado do Rio de Janeiro) em 1985. Cursou Especialização em Língua Inglesa pelo Departamento de Letras da UERJ de março de 1989 a dezembro de 1989. É Mestra em Lingüística Aplicada pela UFRJ (Universidade Federal do Rio de Janeiro).

Ficha Catalográfica

Antunes, Maria Alice Gonçalves

O respeito pelo original : uma análise da autotradução a partir do caso de João Ubaldo Ribeiro / Maria Alice Gonçalves Antunes; orientadora: Márcia Amaral Peixoto Martins. - 2007.

270 f. : il. (col.) ; $30 \mathrm{~cm}$

Tese (Doutorado em Letras)-Pontifícia Universidade Católica do Rio de Janeiro, Rio de Janeiro, 2007.

Inclui bibliografia

1. Letras - Teses. 2. Autor-modelo. 3. Autotradutor. 4. Original. 5. Tradução. I. Martins, Márcia Amaral Peixoto. II. Pontifícia Universidade Católica do Rio de Janeiro. Departamento de Letras. III. Título. 


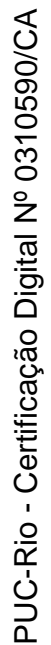

Aos meus pais, à minha irmã e à minha querida Clarinha, sempre. 


\section{Agradecimentos}

A João Ubaldo Ribeiro, pela generosidade.

À professora Dra. Susan Bassnett, pelo interesse demonstrado através de contribuições valiosas e do diálogo constante.

Às professoras Dras. Maria Clara Castellões e Maria Paula Frota e ao professor Paulo Henriques Britto (notório saber), pelas contribuições que fizeram por ocasião do exame de qualificação desta tese.

Às professoras Dras. Leila Cristina de Mello Darin, Maria Aparecida Andrade Salgueiro, Maria Paula Frota, Maria Cristina Batalha e Maria de Lourdes Duarte Sette e ao professor Dr. José Luis Jobim, pela participação na Banca.

Às colegas do setor de inglês, em especial, e do departamento LAG, pelo apoio e pelo interesse.

Aos amigos, pelo incentivo, pelas apresentações em seminários e conversas produtivas e, principalmente, pela paciência.

À Luzia, Beatriz, Mônica e Lúcia Cláudia, pelo incentivo ao início de minha vida acadêmica e pela amizade incondicional.

À jornalista Beatriz Marinho Strauss, por possibilitar meu primeiro contato com João Ubaldo Ribeiro.

À Carolina Alfaro de Carvalho, pela revisão precisa e interessada.

À Francisca Ferreira de Oliveira, Secretária da Pós-Graduação da PUC-Rio, pela eficiência e paciência infinitas. 
À CAPES, pela bolsa para Estágio na Universidade de Warwick, e à PUC-Rio, pelo apoio financeiro.

E, em especial, à Profa. Dra. Marcia Amaral Peixoto Martins, minha orientadora, pelo incentivo a minha entrada no Doutorado, pelo entusiasmo com que acolheu meu desejo de pesquisar a autotradução e o caso de João Ubaldo Ribeiro, pela leitura atenta deste e de outros trabalhos, pelas contribuições valiosas, e por tudo aquilo que eu certamente esqueci de mencionar aqui. 


\section{Resumo}

Antunes, Maria Alice Gonçalves; Martins, Marcia Amaral Peixoto. O respeito pelo original - uma análise da autotradução a partir do caso de João Ubaldo Ribeiro. Rio de Janeiro, 2007. 270p. Tese de Doutorado Departamento de Letras, Pontifícia Universidade Católica do Rio de Janeiro.

Esta tese se insere no âmbito dos estudos descritivos da tradução e investiga a autotradução a partir do caso do escritor brasileiro João Ubaldo Ribeiro. Com base em uma nova concepção do autor-modelo (Eco, 1979a; 1979b; 1994), este estudo investiga se o exercício da autotradução pode ser visto, no caso do escritor brasileiro, como uma possibilidade de continuação, por assim dizer, do processo de escrita original. Para tal investigação, utiliza-se um corpus constituído por: (i) o artigo "Suffering in translation", de autoria de João Ubaldo; (ii) entrevistas (publicadas ou não) e declarações diversas concedidas pelo escritor; (iii) os textos - original e tradução - produzidos por ele; (iv) resenhas escritas por críticos norteamericanos e publicadas nos Estados Unidos; e (v) livros escritos por críticos brasileiros sobre a obra do autor. Utiliza-se ainda instrumentos de pesquisa distintos: (i) a comparação entre original e tradução, freqüentemente feita por estudiosos da tradução; (ii) o modelo para análise de traduções de Lambert e van Gorp (1985); e (iii) a entrevista por e-mail (Mann \& Stewart, 2000). Além da análise do corpus em si, este estudo apresenta um histórico da autotradução e relatos dos casos dos autotradutores Vladimir Nabokov, Samuel Beckett, Milan Kundera, escritores catalães e poetas escoceses. Esta apresentação tem por objetivo proporcionar o diálogo entre as diversas práticas autotradutórias.

\section{Palavras-chave}

Autor-modelo; autotradutor; original; tradução. 


\section{Abstract}

Antunes, Maria Alice Gonçalves; Martins, Marcia Amaral Peixoto Martins (Advisor). Respect for the original text - an analysis of self-translation based on the case of the Brazilian writer João Ubaldo Ribeiro. Rio de Janeiro, 2007. 270p. PhD Dissertation - Departamento de Letras, Pontifícia Universidade Católica do Rio de Janeiro.

The present work presents a study of self-translation based on the case of the Brazilian writer João Ubaldo Ribeiro. Using in the revisited concept of model author, this thesis seeks to analyse whether the practice of self-translation can be seen, in the case of the Brazilian writer, as the continuation of the process of original writing. The elaboration of the answer to this question is based on the analysis of the corpus, which consists of: (i) the article "Suffering in translation", by João Ubaldo Ribeiro; (ii) published and unpublished interviews given by the author; (iii) original and self-translated texts produced by João Ubaldo; (iv) reviews written by North American critics and published in the USA; and (v) books written by professional readers about João Ubaldo's works. Also, the investigation uses different research instruments: (i) the comparative analysis between original and self-translated texts; (ii) Lambert and van Gorp's model for the analysis of translated literature; and (iii) e-mail interview. Besides the analysis of the corpus, this study presents a brief historical account of self-translation and general critical reports of self-translators' - Vladimir Nabokov, Samuel Beckett, Milan Kundera, Catalan writers and Scottish poets - works. Rather than provide readers with a detailed critical analysis of these writers' texts, these reports seek to make the dialogue between distinct self-translation practices possible.

\section{Keywords}

Model-author, self-translator, original, translation. 


\section{Sumário}

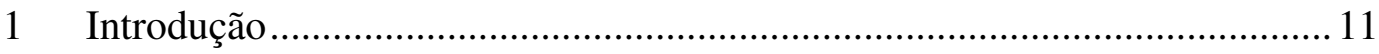

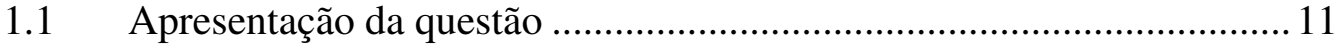

1.2 As origens deste estudo sobre João Ubaldo Ribeiro, autotradutor ........ 15

1.3 A autotradução como objeto de pesquisa .............................................2 24

1.3.1 Objeto, corpus e questões do estudo de caso ..............................25

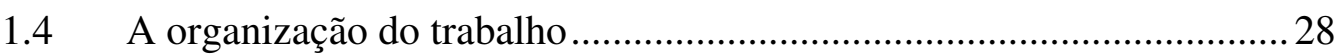

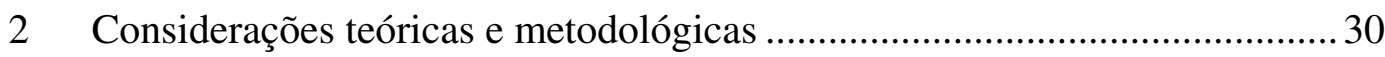

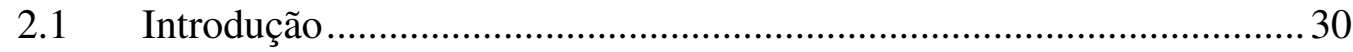

$2.2 \quad$ O autor-modelo de Umberto Eco …….................................................. 30

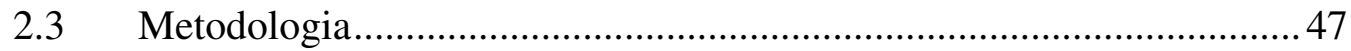

2.3.1 O modelo de Lambert e van Gorp (1985)....................................49

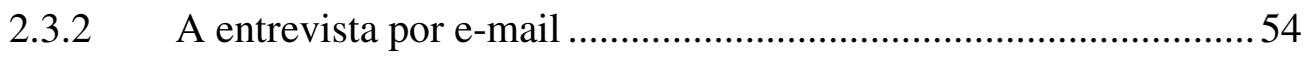

2.3.2.1 A entrevista por e-mail com João Ubaldo Ribeiro ....................57

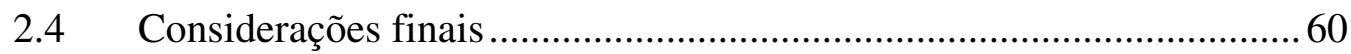

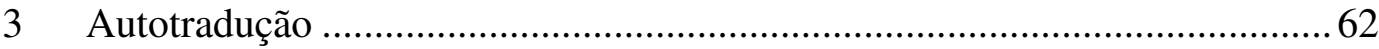

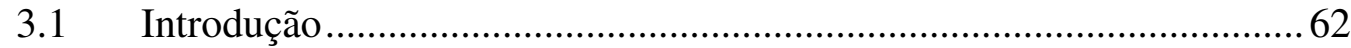

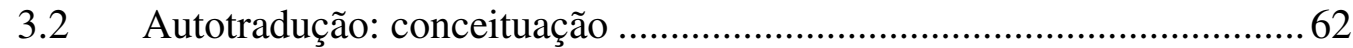

3.3 Breve histórico da autotradução e das pesquisas sobre o tema ..............66

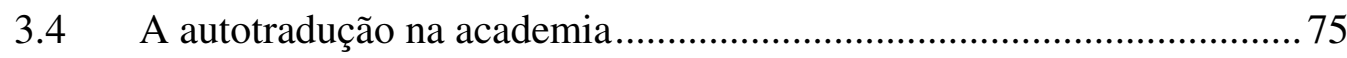

3.4.1 A tese de Helena Tanqueiro: Autotradução - autoridade,

privilégio e modelo ...................................................................................... 76

3.4.2 A tese de Verena Jung: English-German self-translation of academic texts and its relevance for translation theory and practice...........95

3.4.3 A tese de Lillian DePaula Filgueiras: A invenção do original via tradução, pseudotradução e autotradução................................................. 112

3.5 Autotradução e autotradutores: motivações e questões teóricas ......... 121

3.5.1 O caso de Vladimir Nabokov (1899-1977) ................................ 122

3.5.2 O caso de Samuel Beckett (1906-1989) ..................................... 134

3.5.3 O caso de Milan Kundera (1929) .............................................. 143

3.5.4 O caso do autotradutores catalães............................................ 153

3.5.5 O caso dos autotradutores escoceses ....................................... 158 
$4 \quad$ O estudo de caso sobre João Ubaldo Ribeiro ............................................. 163

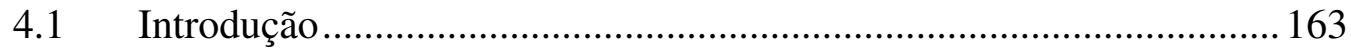

4.2 João Ubaldo Ribeiro: biografia resumida ............................................. 164

4.3 O caso de João Ubaldo Ribeiro: as pré-condições e o tipo de

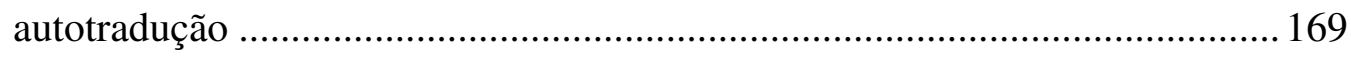

4.4 O processo de publicação e os paratextos ............................................ 177

4.5 Original e tradução: análise comparativa ........................................... 194

4.5.1 Os itens de especificidade cultural .............................................209

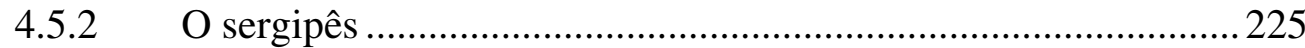

4.5.3 Os erros em Viva o povo brasileiro ............................................. 231

4.5.4 As alterações mais significativas .............................................. 233

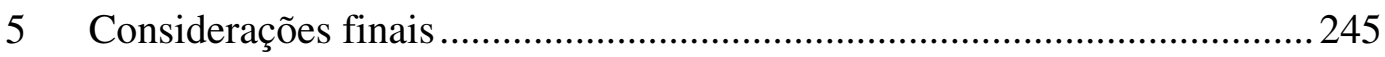

6 Referências Bibliográficas....................................................................252

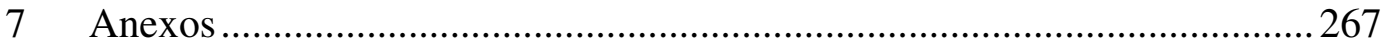

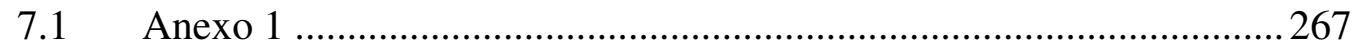

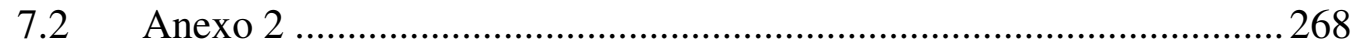

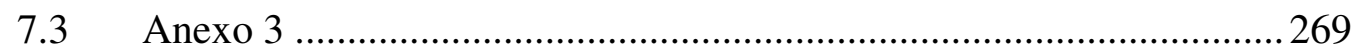

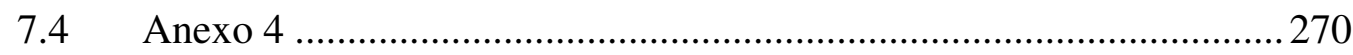

